\title{
Multihospital System Affiliation as a Survival Strategy \\ for Rural Hospitals Under \\ the Prospective Payment System
}

\author{
Michael T. Halpern, Jeffrey A. Alexander, and Mary L. Fennell
}

\begin{abstract}
The introduction of Medicare's Prospective Payment System (PPS) has disproportionately increased financial pressures on rural hospitals and posed challenges to the survival of these institutions. Increasingly, rural hospitals are seeking strategies that can enhance their chances for survival in a turbulent and hostile environment. This study examined the survival effects of one such strategy, multihospital system affiliation. Specifically, we assessed: (1) whether and how different types of system affiliation in the post-PPS era affect the likelihood of rural hospital survival; (2) whether particular structural, environmental and hospital performance characteristics moderate the effects of system affiliation on rural hospital survival; and (3) whether systematic selection by rural hospitals into multihospital systems potentially accounts for observed relationships between system affiliation and survival.

Proportional hazards analyses indicate that system affiliation with investor-owned systems significantly reduces survival probabilities of rural hospitals. Affiliation with not-for-profit systems or system affiliation under contract management arrangements does not affect survival probabilities of rural hospitals.

These general findings are moderated by the effects of hospital ownership and size at the time of affiliation. Finally, study findings indicated that systematic selection by poor performing rural hospitals into investor-owned systems has occurred in the post-PPS era. No evidence of selection into not-for-profit systems was discovered.
\end{abstract}

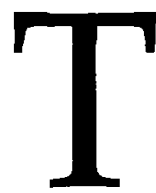

he economic changes created by

Medicare's Prospective Payment System (PPS) have posed a threat to the survival of rural hospitals. Rural hospitals serve disproportionately more patients in categories affected by this change, including indigents and the elderly (Hart, Amundson, \& Rosenblatt, 1990; Moscovice, 1989). In addition, rural hospitals often receive lower reimbursements than urban hospitals for the same procedures due to urban/rural payment differentials (Moscovice, 1989). Problems posed by PPS in rural areas have been

This research was supported by National Science Foundation grant number SES-8821592. Additional support was provided by the Center on Aging and Health in Rural America at Pennsylvania State University. For further information, contact: Michael T. Halpern, The University of Michigan, Public Health Policy and Administration, M4110 School of Public Health II, 1420 Washington Heights, Ann Arbor, MI 48109-2029. 
exacerbated by other economic challenges to rural hospitals, including decreased revenues, increased liability concerns, loss of patients to urban facilities, shortage of capital, and declining operating margins (Government Accounting Office, 1990; Mick \& Morlock, 1990).

As rural hospitals are being challenged by PPS and other concomitant environmental changes, many are considering available strategic options that can potentially enhance their chances for survival. This study examined whether the strategy of multihospital system affiliation in the post-PPS environment affects the survival probabilities of rural hospitals. Specifically, we investigated three issues: (1) whether and how different types of multihospital system affiliation affect the likelihood of rural hospital survival; (2) whether structural, environmental, and performance characteristics of hospitals moderate the effects of multihospital system affiliation on rural hospital survival; and (3) whether systematic selection by rural hospitals into multihospital systems potentially accounts for observed relationships between system affiliation and survival.

\section{Background}

Multihospital System Strategies. Although studies of hospital closure have been abundant (Cannedy, Pointer, \& Ruchlin, 1973; Kennedy \& Dumas, 1983; Mayer, Kohlenberg, Sieferman, \& Rosenblatt, 1987; Muller \& Whiteis, 1988; Mullner, Rydman, Whiteis, \& Rich, 1989; Mullner \& McNeil, 1986), relatively few have examined the effects of multihospital system affiliation on rural hospital viability and survival. Those that have generally report mixed findings. Longo and Chase (1984), in examining closure of all hospitals, compared hospitals that closed to hospitals that merged with one or more hospitals, joined a multihospital system, or remained open and autonomous. They found that the characteristics of hospitals that closed resembled those of hospitals that became part of mergers, while the characteristics of hospitals that affiliated with multihospital systems resembled those that remained open and autonomous. Additional multivariate analyses were performed to examine the independent effect of a number of factors on hospital closure, but system affiliation was not among them.

Mullner et al. (1989) specifically examined the effect of system affiliation on rural hospital closure. Affiliation with a multihospital system was found to be protective for rural hospitals in two ownership categories: investor owned and voluntary non-profit. Finally, a recent study by Barry, Tucker, and Seavey (1990) found that system affiliation by rural hospitals affected hospital performance only as measured by Joint Commission on Accreditation of Healthcare Organizations (JCAHO) accreditation. System hospitals were more likely to receive accreditation than were those that were not system affiliated. No other performance measures showed a significant difference between affiliated and independent hospitals.

At least four theoretical and research design issues limit the utility of these studies. First, previous studies of multihospital system affiliation by rural hospitals have not separated hospitals by type of system affiliation. To the extent that acquisition and operating strategies differ across systems, affiliation with different types of systems can potentially have very different effects on the likelihood of rural hospital survival (Alexander \& Morrisey, 1988, 1989).

Second is the issue of right censoring. Studies of hospital closure can only examine closures that occur within a delineated period; by definition, closures that occur after the study period cannot be known or predicted with certainty. In previous studies, hospitals that remained open through the end of a study period have typically been treated as not closing. In reality, however, some or all of these hospitals may close at some point in the future. Ignoring the effect of such right censored observations can lead to seriously biased estimates when modeling the occurrence of organizational "events" such as closure.

Third is the issue of time dependence. Within a study period, dynamic events such as system affiliation do not occur at the same time for all hospitals under study. Some hospitals may affiliate early in the study period, while others affiliate later. The effect of system affiliation can be studied for longer durations for hospitals that affiliate early in the study period, while the effect of affiliation may not be detectable for hospitals joining systems near the end of the study. Models that do not take this temporal variation into account are, in effect, evaluating the effect of affiliation on survival uniformly from a single point in the study period.

A fourth issue involves specification of the conditions under which system affiliation would be appropriate for rural hospitals. Advantages (or disadvantages) of system affiliation may be moderated by economic, structural, and environmental conditions present at the time of affiliation. Ignoring 
such potential moderating effects may lead to inappropriate strategic action for significant subsets of rural hospitals. As discussed by Smith and Piland (1990), "rural hospitals must evaluate the applicability of strategies in light of their particular environmental and organizational structures."

Hypotheses. A strategy frequently advocated by many hospital experts to improve the financial viability and survival of rural institutions is linkage with a larger health care or hospital system (MHS). The touted benefits of MHS affiliation include economies of scale related to joint purchasing or shared service agreements; operating efficiencies in the form of increased productivity, lower staffing requirements, and lower per unit costs; and improved access to capital financing (Zuckerman, 1979; Ermann \& Gabel, 1984).

Research evidence regarding the benefits of such affiliation, however, is decidedly mixed (Ermann \& Gabe, 1984, Shortell, 1988). Indeed, a frequent but questionable assumption of studies on multihospital system performance has been that hospitals affiliating with different systems benefit from similar operating advantages. However, systems may vary on a number of important dimensions, including locus of control (Alexander \& Fennell, 1986), acquisition criteria (Alexander \& Morrisey, 1988; Alexander et al., 1985), and operating strategies (IOM, 1986; Ermann \& Gabel, 1984; Shortell, 1988). The latter may include growth, scale economies, the attainment of monopoly power, or market penetration (Morrisey \& Alexander, 1987). Such strategic differences have been systematically linked with three types of multihospital system arrangements: not-for-profit multihospital systems, investor-owned multihospital systems, and contract management arrangements (Alexander \& Morrisey, 1988; Morrisey \& Alexander, 1987). Because of differences in operating strategies among these three types of system arrangements, the survival chances of rural hospitals affiliating with each of the three types may also differ.

Both not-for-profit and investor-owned systems considering the acquisition of a rural hospital must look at the same market and management factors. Ideally, these would be situations in which the opportunities to improve hospital performance would be bolstered by favorable market conditions and weak current management structure. Not-forprofit systems, however, may be willing to relax some of these criteria because their strategic goals may include those other than profit. That is, not-for- profit systems may be more likely to acquire hospitals in poor market situations. At the same time, notfor-profit systems relative to investor-owned systems may be less likely to divest themselves of marginal hospitals because of institutional constraints (Alexander \& Morrisey, 1988). By contrast, the fiduciary obligations of investor-owned systems to their stockholders may compel them to quickly withdraw support from a failing rural hospital if it cannot be turned around or if the system changes its strategic direction. Such actions are facilitated by the relatively weak links between investor-owned facilities and community and government interests (Rose, 1983). Thus, all things being equal, risk of closure will be lowered by rural hospital affiliation with not-for-profit systems, but will increase through affiliation with investor-owned systems by virtue of the more rigorous market criteria applied by such systems (e.g., profitability) coupled with weaker community support.

These arguments lead to the following hypotheses.

Hypothesis 1. Ceteris paribus, rural hospitals affiliating with investor-owned systems in the post-PPS era experience higher risk of closure than rural hospitals that did not affiliate with investor-owned systems.

Hypothesis 2. Ceteris parabis, rural hospitals affiliating with not-for-profit multihospital systems in the post PPS era experience lower risk of closure than rural hospitals that did not affiliate with not-forprofit multihospital systems.

Contract management is a third form of system affiliation, characterized by a situation in which the governing board of a hospital assigns the duties of managing the day-to-day operations of the institution to an organization other than the hospital. The board retains full control over hospital policy. Much of the literature views contract management as a means by which hospitals can acquire depth in management expertise and experience without sacrificing institutional autonomy and independence. From the system's perspective, however, management contracts may be undesirable because the system cannot exercise enough control over the operations of the managed hospital (Morrisey \& Alexander, 1987; Alexander, \& Morrisey 1989). Because of these severe operating constraints, we expect that externally provided management expertise will not be sufficient to extricate distressed rural hospitals from their predicament. Therefore, we anticipate that contract 
management will be ineffective as a strategy for lowering the risk of rural hospital failure.

We therefore formulated the following hypothesis.

Hypothesis 3. Ceteris paribus, rural hospitals affiliating with multihospital systems through contract management in the postPPS era experience no difference in risk of closure relative to rural hospitals that did not affiliate with multihospital systems through contract management.

To this point, our theoretical discussion has focused on general survival benefits of system affiliation by rural hospitals under PPS. A second related issue concerns the joint effects of system affiliation and hospital characteristics on survival chances for rural hospitals. That is, does system affiliation affect survival probabilities differentially as a function of type of hospital or conditions of affiliation? For example, it may be beyond the management capabilities of systems to improve the survival probabilities for very small, poorly performing rural hospital affiliates. On the other hand, the risk of failure may be significantly reduced for smaller, more vulnerable hospitals that affiliate with systems, since they have the most to gain from such affiliation. After testing the main effects models, we explore whether such predisposing hospital characteristics mediate the effects of system affiliation on hospital survival.

Covariates. In examining the relationship of rural hospital survival and multihospital system affiliation, a number of additional covariates are considered. These variables will be employed both as control variables to rule out alternative explanations for the relationship between system affiliation and rural hospital survival and to test the hypothesis that hospital predisposing characteristics mediate this relationship.

Size. The literature suggests that larger hospitals have greater likelihoods of survival. Barry, Tucker, and Seavey (1990) reported that larger rural hospitals (50 to 100 beds, as compared to rural hospitals with fewer than 50 beds) were more likely to have higher occupancy rates, longer average length of stays, fewer employees per bed, and were more likely to be accredited. Moscovice (1989) also reported that the smallest rural hospitals are the least profitable and the most likely to have negative operating margins. Because these factors can directly affect rural hospital survival, we control for such effects by including a variable reflecting the number of beds operated by the hospital.

Sole provider status. When only a single hospital exists within a rural community, there may be additional incentives for such a hospital to remain in operation (e.g., community support, strong institutional ties). Further, under PPS, additional support is available for sole community hospitals (Moscovice, 1989). These factors may be offset, however, since sole providers are generally smaller than other rural hospitals and have higher average costs (Moscovice, 1989). We therefore control for hospitals operating as the sole health care provider within a given market area.

Ownership. Because rural hospitals of different ownership (governmental, religious, secular not-forprofit, or investor owned) may have differing underlying missions, operating strategies, and/or predispositions to affiliate with (or be acquired by) multihospital systems, we control for the effect of hospital ownership on rural hospital survival.

Prior system affiliation. Accounting for hospital affiliation with multihospital systems prior to the start of the study period (1983) is necessary to accurately reflect the risks of both new system affiliations within the study period and to differentiate between those hospitals that engaged in system affiliation in response to PPS from those that affiliated earlier. We therefore control for extant system membership at the start of the study period (1983).

Performance stage. A hospital's long-term operating performance has a direct influence on its continued survival. Further, such performance may be important in systematic selection of rural hospitals into multihospital systems, as discussed above. We therefore control for hospital performance stage, a variable indicating whether the hospital is in a period of growth, decline, stability, or instability.

\section{Methods}

Sample and Data. Data were collected from the American Hospital Association (AHA) Annual Surveys of Hospitals, years 1983 through 1988. The AHA Annual Survey of Hospitals is administered in the fourth quarter of each year to all AHA registered and non-registered facilities ( $\mathrm{N}=6,800)$. Except for minor modifications, the survey remained unchanged throughout the study period. Data were also derived from the AHA Multihospital System Directory and other published and unpublished sources. 
The sample used for the current study was a panel of 2705 community hospitals that were: (1) in operation in 1983, and (2) located in rural areas, designated as operating outside of a Standard Metropolitan Statistical Area (Note 1).

\section{Measurement.}

Hospital closure. The dependent variable for this study is based on whether or not hospital closure occurred in each year from 1984 to 1988 . This variable was derived from the Deletions section of the AHA Summary of Registered Hospitals and validated by independent lists produced by the AHA. In addition to complete cessation of operations, the AHA definition of closure includes shifts by hospitals from providing acute inpatient care to either another form of inpatient care (i.e., residential care), outpatient care only, or non-health care services. Partial conversion is not considered closure as long as the hospital continues to provide some acute inpatient care (Note 1).

Independent variables. Six variables were constructed to model the relationship between multihospital system affiliation and rural hospital survival.

1. Multihospital system affiliation.

Information on system affiliation was prepared by comparing consecutive years (in the study period) of the AHA Multihospital System Directory. Changes in status of individual hospitals with respect to system affiliation and additions to systems were identified. Three different classes of affiliation were examined: membership in a not-for-profit system in an owned, leased, or sponsored capacity; membership in an investor-owned system in an owned, leased, or sponsored capacity; and contract management by a system of any ownership status. System affiliation was coded as a timedependent variable, recording not only the type of affiliation (if any) occurring within the study period, but also the year within the study period when the affiliation took place. Thus, for each class of system affiliation, two variables were created: one dichotomous variable indicating affiliation (1) or no affiliation (0) within the six years of the study period (1983-88), and the second variable indicating during which year (if any) of the study the affiliation occurred (Note 2).

2. Prior system affiliation.

Prior (pre-1983) affiliation with investorowned, not-for-profit, or contract management was coded as separate dichotomous variables: prior affiliation (0) versus no prior affiliation (1). This information was derived from the 1983 AHA survey.

3. Hospital Size.

Size was measured as the number of hospital statistical beds, as recorded by the $1983 \mathrm{AHA}$ survey. Statistical beds refers to "the average number of beds set up and staffed for use during the reporting period."

4. Sole Provider Status.

Hospitals were designated as sole providers if no other general acute care hospital operated within a 15-mile radius. This information was derived from the Hospital Neighbor File (Luft \& Maerki, 1985). The sole provider variable status was coded dichotomously, sole provider (1) versus not a sole provider (0).

5. Hospital Ownership.

Ownership was derived from the 1983 AHA survey. All hospitals were placed in one of four mutually exclusive ownership categories: government, religious, secular not-for-profit, or investor owned. Secular not-for-profit hospitals was the omitted reference category in multivariate analyses.

6. Performance Stage.

Following Cameron and colleagues (Cameron, Kim, \& Whetten, 1987a; Cameron, Whetten, \& Kim, 1987b; Whetten, 1987), hospitals were placed into one of four mutually exclusive performance stages for the period 1980-1984: decliners, growers, stable, or unstable. Performance cycle was determined by patterns of adjusted admissions of hospitals in the sample, where adjusted admissions are the sums of admissions and equivalent admissions attributed to outpatient services (product of admissions and ratio of outpatient revenue to inpatient revenue). Patterns of changes in adjusted admissions of an individual hospital were compared to mean changes for that hospital's industry comparison group. Nine mutually exclusive comparison groups were formed on the basis of ownership category (secular not-for-profit, religious not-forprofit, or government), and within each ownership category, three groups were formed based on hospital bed size (fewer than 100 beds, between 100-299 beds, 300 or more beds). Hospitals showing increases in adjusted admissions of more than 5 percent above the average change for their comparison groups for at least three of the four consecutive years pairs (1980-81, 81-82, 82- 
$83,83-84$ ) were categorized as growers, while those showing decreases of more than 5 percent below national averages for at least three of four year pairs were designated as decliners. Hospitals showing at least one year pair of consecutive years with adjusted admissions growth greater than 5 percent and at least one year pair of adjusted admissions decline greater than 5 percent with respect to their comparison groups were classified as unstable. All remaining hospitals were classified as stable. Numbers of adjusted admissions for this time period were taken from the 1980-1984 AHA Annual Survey of Hospitals.

Analytic method. Models were evaluated using proportional hazards regression (Cox, 1972). This is a semi-parametric technique where the underlying baseline risk (here, the baseline risk of rural hospital closure), also known as the hazard, is an unspecified function of time. Risk of closure for any hospital is proportional to this baseline risk, and the exact level of risk depends on the hospital's covariates. The relative risk of closure with certain covariates or covariate combinations can thus be determined.

Proportional hazards models involve two variables (Allison, 1985). The first is an event variable, to indicate whether the activity under study (here, multihospital system affiliation by a rural hospital) has occurred. The second is a censoring variable. This variable is needed, as discussed above, because this analysis ends before all the hospitals involved in the analysis close. Given an infinite amount of time to observe rural hospitals in this study, all hospitals would eventually close. However, as a study of infinite duration is not feasible, the number of years a given hospital has been observed and the number of hospitals that close during these years suggests the rate at which other hospitals in the study will eventually close.

The hazard rate for rural hospital closure was measured by estimating the following model:

$\mathrm{r}_{\mathrm{jk}}(\mathrm{t})=\exp \left(\underline{\mathrm{a}}_{\mathrm{jk}} \mathrm{X}(\mathrm{t})\right)$

where $r_{j k}$ is the rate of transition from state $j$ (operational) to state $\mathrm{k}$ (closed), $\mathrm{X}(\mathrm{t})$ is a vector of covariate values at time $t$, and $\underline{a}_{j k}$ is a vector of parameter estimates determined by partial likelihood estimation. Transition rates are postulated to be log linear functions of the variables in vector $X$.

The time-dependent nature of multihospital system affiliation is incorporated into the proportional hazards regression by setting the affiliation variable initially to zero. The affiliation variable is revalued to one in the year in which an affiliation took place. If multihospital affiliation does not occur during the study period, the affiliation variable remains zero throughout the regression.

\section{Results}

Descriptive statistics and correlations among study variables are shown in Table 1 . Negative correlations with large magnitudes were found between variables representing different classes of a categorical variable (i.e., between the different types of hospital ownership). These large negative correlations, however, were not unexpected.

Table 2 presents the temporal pattern of system affiliations and closure among rural hospitals during the study period. Yearly closure of rural hospitals generally increased throughout the study period. Overall, approximately 5.9 percent of the study sample closed between 1983 and 1988. Of the three types of multihospital system affiliation examined, contract management was the most frequently observed, occurring in approximately 12 percent of the study panel. Affiliation with investor-owned or not-for-profit systems occurred less often but with similar frequency ( $4.8 \%$ and $5.7 \%$, respectively). With one exception, strong temporal patterns were not evident among or between any of the three affiliation types. Considerably fewer hospitals affiliated with investor-owned and not-for-profit systems in the final year of the study period (1988) than might be expected from extrapolating trends from the preceding years. This may be due to several factors, including shifts in system strategies away from horizontal integration, a reduced pool of "acceptable" acquisition candidates among rural hospitals, and/or perceived lack of efficacy of system affiliation by rural hospitals.

A single base model was specified to examine the main effects of multihospital system affiliation, hospital size, sole provider status, prior system affiliation, hospital ownership, and performance stage on the probability of rural hospital survival. The model was estimated separately for each of the three system affiliation types: affiliation with not-forprofit systems, affiliation with investor-owned systems, or contract management. The three system types are estimated separately because of previous 
Table 1. Intercorrelations and Descriptive Statistics.

\begin{tabular}{|c|c|c|c|c|c|c|c|c|c|c|c|c|c|c|c|}
\hline \multicolumn{2}{|c|}{ Variables } & \multirow{2}{*}{$\begin{array}{c}\text { Mean } \\
0.06\end{array}$} & \multirow{2}{*}{$\begin{array}{c}\mathrm{SD}^{1} \\
0.23\end{array}$} & \multirow[t]{2}{*}{1} & \multirow[t]{2}{*}{2} & \multirow[t]{2}{*}{3} & \multirow[t]{2}{*}{4} & \multirow[t]{2}{*}{5} & \multirow[t]{2}{*}{6} & \multirow[t]{2}{*}{7} & \multirow[t]{2}{*}{8} & \multirow[t]{2}{*}{9} & \multirow[t]{2}{*}{10} & \multirow[t]{2}{*}{11} & \multirow[t]{2}{*}{12} \\
\hline 1. & Hospital closure & & & & & & & & & & & & & & \\
\hline 2. & Statistical beds & 84.71 & 67.61 & -0.14 & & & & & & & & & & & \\
\hline 3. & Sole provider status & 0.48 & 0.49 & 0.08 & 0.14 & & & & & & & & & & \\
\hline 4. & $1983 \mathrm{MHS}^{2}$ affliation & 0.16 & 0.37 & 0.00 & 0.05 & 0.03 & & & & & & & & & \\
\hline 5. & $1983 \mathrm{CM}^{3}$ affiliation & 0.16 & 0.36 & 0.00 & -0.09 & -0.04 & 0.05 & & & & & & & & \\
\hline 6. & Government ownership & 0.45 & 0.50 & -0.05 & -0.20 & -0.18 & -0.33 & 0.04 & & & & & & & \\
\hline 7. & Investor ownership & 0.09 & 0.28 & 0.13 & -0.04 & 0.13 & 0.17 & -0.07 & -0.28 & & & & & & \\
\hline 8. & Religious ownership & 0.08 & 0.26 & -0.01 & 0.11 & 0.06 & 0.26 & -0.01 & -0.26 & -0.09 & & & & & \\
\hline 9. & Secular NFP4 ownership & 0.39 & 0.49 & -0.01 & 0.17 & 0.08 & 0.10 & 0.13 & -0.72 & -0.25 & -0.23 & & & & \\
\hline & Decliner & 0.06 & 0.24 & 0.12 & -0.05 & -0.01 & 0.09 & 0.00 & -0.04 & 0.11 & 0.01 & -0.04 & & & \\
\hline & Grower & 0.10 & 0.30 & -0.05 & -0.06 & -0.03 & -0.02 & 0.05 & 0.09 & -0.09 & 0.00 & -0.05 & -0.09 & & \\
\hline & Stable & 0.34 & 0.47 & -0.00 & 0.16 & 0.02 & -0.06 & -0.10 & -0.05 & 0.03 & -0.00 & 0.03 & -0.18 & -0.24 & \\
\hline & Unstable & 0.53 & 0.50 & -0.04 & -0.12 & -0.01 & 0.04 & 0.07 & 0.03 & -0.05 & -0.00 & 0.01 & -0.27 & -0.11 & -0.77 \\
\hline
\end{tabular}

Correlations greater than or equal to 0.04 are statistically signficant at $P=0.05$.

1. $\mathrm{SD}=\mathrm{Standard}$ Deviation

2. MHS=Multihospital System

3. $\mathrm{CM}=$ Contract Management

4. $\mathrm{NFP}=$ Not-for-profit

evidence that each is potentially distinct with regard to its operating or acquisition strategy (Alexander \& Morrisey, 1989). Collinearity diagnostics were performed separately for each system affiliation model using the method described by Belsley, Kuh, and Welsch (1980). These diagnostics suggest that no significant collinearity occurs in any of the three models.

Table 3 presents results from the aforementioned models. The positive beta coefficients for the system affiliation variables in the three models indicate that system affiliation decreased the likelihood of rural hospital survival (e.g., increased likelihood of closure) for each of the three types of affiliation examined. However, only affiliation with investor-owned systems was statistically significant. In support of hypothesis 1 , this finding indicates that joining an investor-owned multihospital system in the post-PPS era significantly reduced the probability of survival for rural hospitals relative to nonjoiners. This result obtains controlling for performance stage, ownership,
Table 2. Multihospital System Affiliations and Closures Among Rural Hospitals, by Year (1983 to 1988).

\begin{tabular}{lcccc}
\hline & $\begin{array}{c}\text { Investor- } \\
\text { Owned } \\
\text { System }\end{array}$ & $\begin{array}{c}\text { Not-for-profit } \\
\text { System }\end{array}$ & $\begin{array}{c}\text { Contract } \\
\text { Management }\end{array}$ & Closure \\
\hline & & & 39 & -1 \\
1983 & 4 & 7 & 44 & 26 \\
1984 & 36 & 17 & 79 & 20 \\
1985 & 27 & 36 & 54 & 33 \\
1986 & 21 & 46 & 60 & 39 \\
1987 & 34 & 34 & 31 & \\
1988 & 7 & 13 & 327 & 159 \\
\hline Total & 129 & 153 & & \\
\hline
\end{tabular}

1. Because the study group was defined as rural hospitals in operation during 1983, no hospital that closed in 1983 was included in the study. 
Table 3. Proportional Hazard Regression of System Affiliation on Rural Hospital Closure.

System Affiliation

\begin{tabular}{|c|c|c|c|}
\hline & $\begin{array}{l}\text { Investor } \\
\text { Owned }\end{array}$ & $\mathrm{NFP}^{1}$ & $\begin{array}{c}\text { Contract } \\
\text { Management }\end{array}$ \\
\hline Covariate & $\begin{array}{c}\text { betatse } \\
\text { (hazard } \\
\text { ratio) }\end{array}$ & $\begin{array}{c}\text { betatse } \\
\text { (hazard } \\
\text { ratio) }\end{array}$ & $\begin{array}{c}\text { betatse } \\
\text { (hazard } \\
\text { ratio) }\end{array}$ \\
\hline System affiliation ${ }^{2}$ & $\begin{array}{c}1.27 \pm 0.25^{* * * 3} \\
(3.55)^{4}\end{array}$ & $\begin{array}{l}0.13 \pm 0.43 \\
(1.14)\end{array}$ & $\begin{array}{l}0.23 \pm 0.32 \\
(1.26)\end{array}$ \\
\hline Size $-0.02 \pm 0.00^{* * *}$ & $\begin{array}{c}-0.03 \pm 0.00^{* * *} \\
(0.98)\end{array}$ & $\begin{array}{c}-0.03 \pm 0.00^{* * *} \\
(0.98)\end{array}$ & $(0.98)$ \\
\hline Sole provider status & $\begin{array}{c}-0.87 \pm 0.18^{* * *} \\
(0.42)\end{array}$ & $\begin{array}{c}-0.89 \pm 0.18^{* * *} \\
(0.41)\end{array}$ & $\begin{array}{c}-0.90 \pm 0.18^{* * *} \\
(0.41)\end{array}$ \\
\hline $\begin{array}{l}\text { System affiliaion } \\
\text { prior to } 1983\end{array}$ & $\begin{array}{l}-0.26 \pm 0.23 \\
\quad(0.77)\end{array}$ & $\begin{array}{c}-0.22 \pm 0.24 \\
(0.81)\end{array}$ & $\begin{array}{c}-0.08 \pm 0.23 \\
(0.92)\end{array}$ \\
\hline $\begin{array}{l}\text { Hospital ownership: } \\
\text { government }\end{array}$ & $\begin{array}{c}-0.56 \pm 0.20^{* *} \\
(0.57)\end{array}$ & $\begin{array}{l}-0.52 \pm 0.20^{*} \\
(0.59)\end{array}$ & $\begin{array}{l}-0.48 \pm 0.20^{*} \\
(0.62)\end{array}$ \\
\hline $\begin{array}{l}\text { Hospital ownership: } \\
\text { investor }\end{array}$ & $\begin{array}{l}0.32 \pm 0.24 \\
(1.38)\end{array}$ & $\begin{array}{l}0.58 \pm 0.23^{*} \\
\quad(1.78)\end{array}$ & $\begin{array}{l}0.57 \pm 0.23^{*} \\
\quad(1.77)\end{array}$ \\
\hline $\begin{array}{l}\text { Hospital ownership: } \\
\text { religious }\end{array}$ & $\begin{array}{l}0.11 \pm 0.37 \\
\quad(1.11)\end{array}$ & $\begin{array}{c}10.06 \pm 0.37 \\
(1.07)\end{array}$ & $\begin{array}{l}0.01 \pm 0.36 \\
(1.01)\end{array}$ \\
\hline Decliner stage & $\begin{array}{l}0.75 \pm 0.24^{* *} \\
\quad(2.12)\end{array}$ & $\begin{array}{l}0.78 \pm 0.25^{* * *} \\
(2.19)\end{array}$ & $\begin{array}{l}0.75 \pm 0.24^{* *} \\
\quad(2.12)\end{array}$ \\
\hline Grower stage & $\begin{array}{l}-1.02 \pm 0.46^{*} \\
\quad(0.36)\end{array}$ & $\begin{array}{l}-1.05 \pm 0.46^{*} \\
\quad(0.35)\end{array}$ & $\begin{array}{l}-1.06 \pm 0.46^{*} \\
(0.35)\end{array}$ \\
\hline Unstable stage & $\begin{array}{l}-0.21 \pm 0.19 \\
(0.81)\end{array}$ & $\begin{array}{c}-0.25 \pm 0.19 \\
(0.78)\end{array}$ & $\begin{array}{c}-0.26 \pm 0.19 \\
(0.77)\end{array}$ \\
\hline $\mathrm{N}$ & 2,705 & 2,705 & 2,705 \\
\hline $\begin{array}{l}\text { Likelihood ratio } \\
\text { statistic (10 degrees } \\
\text { of freedom) }\end{array}$ & $206.68^{* * *}$ & $185.88^{* * *}$ & $185.47^{* * *}$ \\
\hline
\end{tabular}

1. $\mathrm{NFP}=$ Not-for-profit

2. System affiliation coded as a time-varying, dichotomous variable.

3. Statistical significance of betas is represented as follows:

* $\quad P<0.05$

** $\quad P<0.01$

*** $\quad P<0.001$

4. Hazard ratios are the percentage change in risk of closure for a variable taking on the value of one as compared to the variable being zero. For the hospital size variable, the hazard ratio of 0.98 indicates that the risk of closure for a hospital of $\mathrm{N}+1$ beds has 98 percent of the risk of closure as a hospital of $\mathrm{N}$ beds. sole provider status, hospital size, and prior affiliation with an investor-owned system. Hypothesis 2 predicted that survival probabilities would increase for those rural hospitals affiliating with not-for-profit systems in the post-PPS era. Our results do not support this prediction. Statistically, survival chances of affiliators and nonaffiliators with not-for-profit systems are similar. Finally, we found support for hypothesis 3 in that no statistically significant differences in survival probability obtained between contract management joiners and nonjoiners. As a rural hospital survival strategy, system affiliation appears to be, at best, ineffective in the case of notfor-profit systems or contract management arrangements and, at worst, detrimental if hospitals affiliate with investor-owned systems.

Hospital size significantly increased the likelihood of rural hospital survival in each of the three models. The negative regression coefficients for the size variables reflect decreased likelihood of hospital closure. This finding is consistent with previous studies (Cannedy et al., 1973; Mullner \& McNeil, 1986) that found larger rural hospitals are less likely to close than small rural hospitals. Sole provider status also has a significant protective effect against rural hospital closure in each of the three models. Prior system affiliation or contract management, while in the direction of increasing likelihood of survival, was not significant for any of the three models.

The effects of ownership type on rural hospital survival was assessed relative to the excluded category of secular not-for-profit ownership. The effects of hospital ownership on survival probabilities differed slightly between the three base models. For each of the three models examined, government ownership significantly increased rural hospital survival probabilities, while religious ownership was associated with decreased survival probabilities, although the relationship was not statistically significant. Investor ownership also decreased the likelihood of rural hospital survival, but was statistically significant only for models examining affiliation with not-for-profit systems and contract management. Previous studies have reported that investor ownership increases the risk of rural hospital closure (Mayer et al., 1987).

The effects of performance stage were examined in comparison to the excluded category of stable performance stage. Declining performance stage decreased the likelihood of rural hospital survival significantly, while growing performance stage significantly increased survival likelihood. Unstable 
performance stage also increased survival probabilities of rural hospitals, but was not significant in the model.

Two patterns are particularly notable in the aforementioned results. First, the direction of the coefficients for prior system affiliation (before 1983) are opposite those for post-PPS affiliation with multihospital systems. Although these coefficients were not significant, they do suggest that the period during which hospitals affiliate with systems may affect survival risk among rural hospitals. It is possible, for example, that rural hospitals affiliating with systems after PPS were at greater risk for closure relative to those affiliating prior to the implementation of PPS. Whether this represents different patterns of selection in the post-PPS era, shift in system acquisition strategies, or the possibility that tenure in system may increase survival probabilities cannot be definitively ascertained from our data. Second, in contrast to the findings of previous research, our results suggest that it is not investor ownership, per se, that affects risk of hospital closure. Instead, affiliation with investor-owned multihospital systems appears to be the critical determinant of closure risk.

\section{Moderating Effects on System Affiliation and} Hospital Survival. Our second major research issue concerns whether or not various structural, environmental, or performance characteristics of hospitals have a moderating effect on the relationship between system affiliation and rural hospital closure. Our exploratory analysis of this issue focuses on testing for significant interaction effects between system affiliation and the following variables: hospital size, sole provider status, ownership, and performance stage. As before, we modeled the three affiliation strategies separately: investor-owned systems, notfor-profit systems, and contract management. Twenty-four different models were tested, each predicting closure as a function of the main effects presented in Table 3, plus one interaction term. Table 4 presents only the coefficients for the interaction terms from those models (Note 3 ).

For rural hospitals affiliating with investorowned systems, larger hospitals have significantly decreased likelihoods of survival. This is noteworthy as the main effects of hospital size suggest that as hospital size increases, so do rural hospital survival probabilities. Another way of stating this finding is that larger rural hospitals that affiliate with investorowned systems are at greater risk of closure than larger rural hospitals that do not so affiliate. Large size affords rural hospitals degrees of protection from
Table 4. Moderated Effects of System Affiliation on Rural Hospital Closure'.

\begin{tabular}{|c|c|c|c|}
\hline & \multicolumn{3}{|c|}{ System Affiliation } \\
\hline & $\begin{array}{l}\text { Investor } \\
\text { Owned }\end{array}$ & $\mathrm{NFP}^{2}$ & $\begin{array}{c}\text { Contract } \\
\text { Management }\end{array}$ \\
\hline Covariate interactions & $\begin{array}{c}\text { beta } \pm \text { se } \\
\text { (hazard } \\
\text { ratio) }\end{array}$ & $\begin{array}{c}\text { beta土se } \\
\text { (hazard } \\
\text { ratio) }\end{array}$ & $\begin{array}{c}\text { betatse } \\
\text { (hazard } \\
\text { ratio) }\end{array}$ \\
\hline \multicolumn{4}{|l|}{ System Affiliation $x$} \\
\hline Size $0.02 \pm 0.01 * 3$ & $\begin{array}{c}0.02 \pm 0.01 \\
(1.02)\end{array}$ & $\begin{array}{c}-0.03 \pm 0.02^{\#} \\
(1.00)\end{array}$ & $(0.97)$ \\
\hline Sole provider status & $\begin{array}{c}0.63 \pm 0.47 \\
(1.88)\end{array}$ & $\begin{array}{l}-0.04 \pm 0.89 \\
(0.96)\end{array}$ & $\begin{array}{c}0.35 \pm 0.63 \\
(1.42)\end{array}$ \\
\hline $\begin{array}{l}\text { Hospital ownership: } \\
\text { government }\end{array}$ & $\begin{array}{l}-1.02 \pm 0.57^{\#} \\
(0.36)\end{array}$ & $\begin{array}{c}1.82+1.25 \\
(6.16)\end{array}$ & $\begin{array}{l}0.14 \pm 0.66 \\
(1.16)\end{array}$ \\
\hline $\begin{array}{l}\text { Hospital ownership: } \\
\text { investor }\end{array}$ & $\begin{array}{c}-2.05 \pm 0.56^{* * *} \\
(0.13)\end{array}$ & $\begin{array}{c}2.13 \pm 1.18^{\#} \\
(8.40)\end{array}$ & $\begin{array}{c}-0.68 \pm 1.12 \\
(0.50)\end{array}$ \\
\hline $\begin{array}{l}\text { Hospital ownership: } \\
\text { religious }\end{array}$ & $\begin{array}{c}0.14 \pm 1.13 \\
(1.15)\end{array}$ & -4 & - \\
\hline Decliner stage & $\begin{array}{l}-1.25 \pm 0.71^{\#} \\
(0.29)\end{array}$ & $\begin{array}{c}0.84 \pm 1.03 \\
\quad(2.32)\end{array}$ & $\begin{array}{c}2.15 \pm 1.25^{\#} \\
\quad(8.58)\end{array}$ \\
\hline Grower stage & - & - & - \\
\hline Unstable stage & $\begin{array}{c}0.29 \pm 0.49 \\
(1.34)\end{array}$ & $\begin{array}{c}-0.30 \pm 1.02 \\
(0.74)\end{array}$ & $\begin{array}{c}1.82 \pm 1.08^{\#} \\
(6.16)\end{array}$ \\
\hline
\end{tabular}

1. All moderating results shown were obtained by adding multiplicative interaction terms individually to full models specified in Table 3.

2. NFP=Not-for-profit

3. Statistical signficance of betas is represented as follows: \# $\quad P=0.10$

* $\quad P<0.05$

** $\quad P<0.01$

*** $P<0.001$

4. Missing values indicate an empty cell for an interaction with respect to the dependent variable (i.e., no hospitals under religious ownership, joined a not-for-profit system, and subsequently closed in the study period).

closure that are lost when they join an investorowned system. Hospitals under government or investor ownership that affiliate with investor-owned systems experienced significant increases in the likelihood of survival during the study period related to their nonaffiliating counterparts. Finally, relative to hospitals in stable performance cycles, declining hospitals that affiliate with investor-owned systems experience a reduced likelihood of closure. Although 
this interaction was only significant at the $P<0.10$ level, it is noteworthy in light of the fact that the main effects of declining performance are associated with reduced survival probabilities for rural hospitals. This suggests that poorly performing hospitals joining investor-owned multihospital systems may improve their chances of survival relative to the option of not joining an investor-owned system.

In general, mediating effects of hospital characteristics on the relationship of system affiliation and hospital survival were weaker in both the not-forprofit system and contract management models. In the not-for-profit system model, affiliation by a freestanding investor-owned hospital with a not-forprofit system reduced the survival probability of these hospitals, but this effect was again only significant at $P<0.10$. All other interaction terms in the notfor-profit system model failed to achieve statistical significance. It is notable that the interaction of investor ownership with system affiliation differs in direction both when comparing the investor-owned to the not-for-profit model. Affiliation with an investor-owned system increases survival probabilities of investor-owned hospitals, but affiliation with a not-for-profit system reduces survival probabilities for these same hospitals.

In the contract management model, three interaction terms proved significant. The negative coefficient of the size interaction term suggests that rural hospitals increase their chances of survival under contract management under conditions of increasing size $(P<0.10)$. However, declining and unstable hospitals experienced reduced survival probabilities when affiliating with systems under contract management arrangements. This contrasts with the pattern of results in the investor-owned model in which decliners might improve their survival chances if affiliating with an investor-owned system.

In general, the pattern of findings indicates that the effects of system affiliation strategies on hospital survival are, in some cases, conditioned by type of hospital that affiliates, performance stage at the time of affiliation, and type of affiliation strategy pursued by the rural hospital. While these interaction-based findings do not obviate the results of the main effects model, they do suggest system affiliation may be preferred under some conditions and eschewed under others as rural hospitals consider strategies for survival.

Selection Into Multihospital Systems. An enduring theme of the literature on multihospital system performance is the issue of selection bias (Ermann \& Gabel, 1984). For example, rural hospitals joining a multihospital system, or a particular type of multihospital system, may be significantly different in terms of survival potential than hospitals that do not join systems. The observed impact of system affiliation on hospital survival would therefore merely be a proxy for the underlying differences between joiners and non-joiners. Previous studies have recognized such selection as a potential problem, but have done little to address it. Mullner et al. (1989), for example, reported that hospitals with a more favorable financial status may be more likely to join (or to be accepted by) multihospital systems and, therefore, less likely to close. Similarly, Barry, Tucker, and Seavey (1990) found that multihospital systemaffiliated hospitals were more likely to be located in areas with high population growth rates and less competition (as measured by hospital beds per 1,000 population) as compared to independent hospitals.

To address the selection bias issue, we compared performance characteristics of hospitals in the study panel that did or did not affiliate with multihospital systems. These characteristics included measures of long-term performance stage and 1983 operating margin. Table 5 presents the results of these performance comparisons.

Rural hospitals that joined investor-owned systems were significantly more likely than nonjoiners to be in a declining performance stage and significantly less likely to be experiencing unstable performance relative to non-joiners. The operating margins of rural hospitals affiliating with investorowned systems tended to be significantly lower than those of rural hospitals that did not affiliate with these systems. In general, these results suggest that investor-owned systems were more likely to purchase hospitals with poorer performance characteristics, indicating a degree of systematic selection into these systems on the basis of such performance.

No significant differences between joiners and non-joiners of not-for-profit systems were observed. This suggests that self-selection, either on the basis of low or high performance, does not operate in rural hospital affiliation with not-for-profit systems in the post-PPS era. Finally, hospitals affiliating under contract management arrangements with systems tended to be more unstable in their performance than non-contract management hospitals during the study period. No differences, however, were observed in operating margins between those rural hospitals affiliating under contract management versus those that did not engage in such strategies. 
Table 5. Performance Comparisons of Hospitals Affiliating and Not Affiliating with Multihospital Systems (1983 to 1988)1.

\begin{tabular}{lcccccc}
\hline & \multicolumn{1}{c}{$\begin{array}{c}\text { Investor } \\
\text { Owned }\end{array}$} & Not-for-profit & $\begin{array}{c}\text { Contract } \\
\text { Management }\end{array}$ \\
\hline $\begin{array}{l}\text { Performance } \\
\text { characteristic }\end{array}$ & No & Yes & No & Yes & No & Yes \\
$\begin{array}{l}\text { Percent decliner } \\
\text { stage }\end{array}$ & 11.75 & $11.63^{* * 2}$ & 5.92 & 7.84 & 6.18 & 4.89 \\
$\begin{array}{l}\text { Percent grower } \\
\text { stage }\end{array}$ & 6.44 & 5.43 & 6.35 & 7.19 & 6.43 & 6.12 \\
$\begin{array}{l}\text { Percent stable } \\
\text { stage }\end{array}$ & 34.12 & 37.98 & 34.60 & 29.41 & 34.95 & $29.66^{*}$ \\
$\begin{array}{l}\text { Percent } \\
\text { unstable stage }\end{array}$ & 53.69 & $44.96^{*}$ & 53.13 & 55.56 & 52.44 & $59.33^{*}$ \\
$\begin{array}{l}\text { Mean } \\
\text { operating } \\
\text { margin }\end{array}$ & 0.026 & $0.007^{*}$ & 0.026 & 0.015 & 0.026 & 0.020 \\
\hline
\end{tabular}

1. Comparisons made between hospital groups that either did (yes) or did not (no) engage in specific type of multihospital system affiliation during the study period (1983 to 1988).

2. Statistical significance is indicated as follows:

* $\quad P<0.05$

** $\quad P<0.01$

Statistical significance was determined by Fisher's Test (one tailed) for performance cycle variables and by $t$ test for operating margin.

3. Mean 1983 operating margin ws calculated as (total 1983 revenues - total 1983 expenses) $\div$ (total 1983 revenues).

\section{Discussion}

We proposed in this investigation that the risk of rural hospital closure would be greater for hospitals joining investor-owned systems, smaller for hospitals joining not-for-profit systems, and essentially unchanged by affiliating with a contract management system. Our results show that regardless of system type, system membership is not an effective strategy for rural hospitals to reduce closure odds. Affiliation with not-for-profit systems and contract management arrangements has no significant impact on the likelihood of closure, and affiliation with investor-owned systems actually increases the likelihood of closure.
These results describe the efficacy of system affiliation within the rural hospital sector following the implementation of Medicare's PPS (post-1983). We also examined, however, whether or not rural hospitals that had joined systems prior to 1983 improved their survival chances in the post-PPS era. Although not statistically significant, the effect of earlier system affiliation on the hazard of closure was negative across all three types of systems examined here, i.e., closure was somewhat less likely for early system joiners. This may be interpreted as evidence that the strategic value of system affiliation in rural areas has itself changed as a result of PPS. Early system joiners may have reaped the alleged benefits of cost savings and improved access to capital markets. Whether the profile of early joiners has changed as well cannot be ascertained with our data. Post-PPS system joiners in rural areas do not appear to be significantly different from nonjoiners of notfor-profit or contract management systems, although rural hospitals joining investor-owned systems do seem to be generally poorer performers. It may be, however, that system affiliation in the post-PPS era is now part of the general "downward spiral" of the rural hospital industry (Hambrick \& D'Aveni, 1988), and once the spiral starts, not even extraordinary measures can necessarily stop its course. Clearly, however, a much longer time series is needed to adequately compare pre- and post-PPS system affiliation strategic value.

The question of whose strategy is implementedthe hospital's or the system's - when a hospital affiliates with a system cannot be answered by these analyses. In any given affiliation, a complex balance of negotiations and bargains are struck by both the subject hospital and the interested system. Whether the hospital approaches the system first or the system targets the hospital cannot be captured by secondary data such as these from the Annual Survey of Hospitals. Nonetheless, we examined possible patterns of "selection" characteristics, specifically performance indicators of rural hospitals that did and did not join systems between 1984 and 1988. These analyses revealed significant differences primarily between hospitals that did and did not join investor-owned systems during the study period. In general, rural hospitals joining (or being purchased by) investorowned systems were poor performers. A number of different possibilities may explain this "selection" effect. It may be that investor-owned systems routinely focus on hospitals with records as poor performers, perhaps as a way of targeting possible "bargains" for takeover. It is also possible that 
investor-owned systems are more likely to pursue growth (i.e., takeovers) for growth's sake, thus extending their systems to pick up both solid and poor performers, particularly in rural areas where a number of possible "targets" can easily be found. Alternatively, investor-owned systems may be more likely to purchase declining hospitals if they are particularly confident of their management strategies and their ability to turn decliners into stable or growing concerns. Obviously, however, the utility of these explanations must be evaluated in future research on system affiliation in rural areas.

Finally, under what conditions is multihospital system affiliation a reasonable strategy for rural hospitals, even though the "safety-net effect" of system affiliation in the post-PPS era is not to be found? Hospital closure is influenced both by hospital operating characteristics (Government Accouting Office, 1990b) and strategic management activity (Ermann, 1990). However, as discussed by Mick and Morlock (1990), the "causal connection between factors correlated with closure is unclear." To understand factors influencing closure of rural hospitals, it may be important to examine strategic options employed by rural hospitals under certain operating conditions. Again, in our main effects model we obtained statistically significant results primarily for hospitals joining investor-owned systems. In brief, affiliation with investor-owned systems increases the chances of closure for rural hospitals, and this result is statistically significant even when controlling for the effect of hospital performance. Given the importance of bottom-line considerations for investorowned systems, it may be that such systems are more likely to close down unprofitable or marginally profitable hospitals, or perhaps to do so more quickly, compared to other types of systems. The influence of not-for-profit affiliation or contract management on hospital closure was not significant.

The influence of system affiliation on rural hospital closure may be somewhat modified, however, by both hospital ownership and size. Investorowned rural hospitals that have affiliated with investor-owned systems are somewhat less likely to close; however, affiliation with not-for-profit systems by investor-owned hospitals seems to increase the risk of closure. This would suggest a "homophilylike" effect in the for-profit sector, where the transition from freestanding to investor-owned system hospital is more easily traversed by investor-owned hospitals. Larger hospitals joining investor-owned systems, however, are at greater risk of closure. Investor-owned systems may be less capable of rescuing larger rural hospitals, but the range of hospital sizes usually found in rural communities tends to be smaller than the national range: hospitals with about 200 beds in rural areas are considered fairly large. Nonetheless, it may be that investorowned system affiliation is a reasonable strategy for a rather limited group of hospitals in rural areas: small investor-owned hospitals.

For whatever reasons rural hospitals seek multihospital system affiliation, or systems seek to acquire rural hospitals, these analyses show that the link between system affiliation and rural hospital closure in the post-PPS era is grimmer than most industry observers have previously thought. Closure is not made less likely by affiliation with either notfor-profit systems or contract management arrangements, and is actually more likely following affiliation with investor-owned systems. Given the fact that these results control for a variety of possible predisposing characteristics that may influence system affiliation effects on closure, and that the study examines closure during a six-year period, the findings appear fairly robust.

An important caveat of the current study concerns the definition of closure employed as our dependent variable. It is important to reiterate that closure need not entail a complete cessation of operations as an organization, but may encompass conversion to a non-hospital health care facility. This means that "survival," in the context of the current analysis, should be viewed as survival for the hospital as an inpatient, acute care delivery organization. For example, investor-owned systems, as a part of their corporate strategy, may convert acquired acute care facilities to long-term care facilities or nursing homes. Greater access to capital and management expertise may facilitate such conversions among hospitals participating in multihospital systems. For purposes of the current study, it is necessary to emphasize again that non-survival of a rural hospital does not necessarily equate with absence of a health care presence in rural communities.

The research questions addressed in this investigation were centered on the effects of affiliating or not affiliating with a multihospital system. Whereas this issue has clear relevance for hospital decisionmakers, there are other important questions that remain to be answered. For example, a competing risk analysis might be undertaken to answer the question of how affiliation with one type of system affects survival chances relative to other strategic options. The data requirements for such analyses are exceedingly complex. Yet, the notion of competing 
risks based on an assessment of the relative efficacy of alternative strategies may be a more realistic (and ultimately more useful) approach given the choices faced by decision makers in many rural hospitals. For example, rural hospital management and trustees often simultaneously deliberate on whether or not to join a non-profit multihospital system, enter into a contract management arrangement with an investorowned system, or engage in diversification by starting a long-term care facility. The central concern for these decision makers would be the relative benefits these alternative strategies hold for institutional viability and survival.

\section{Notes}

1. Hospitals with missing data for sole provider status or performance state were eliminated from the study population.

2. There exists a small probability that a hospital may experience more than one system affiliation during the study period. Nationally, the rate of multiple strategic events during a nineyear (1980-1988) period is quite low, about 4 percent. This includes both repeated events, such as one hospital experiencing both a system affiliation and a corporate restructure. A closer examination of those cases where more than one system affiliation event occurred during the nine-year period revealed that most of those were hospitals reporting affiliation with a system for two consecutive years; in other words, these were singular events unfolding during a two-year period.

3. We were unable to examine certain potential moderating effects, as these represented an empty set, i.e. no hospital in the study panel had religious ownership, joined a not-forprofit system, or closed during the study period. Thus, values for these moderating effects are left blank.

\section{References}

Alexander, J., \& Fennell, M. (1986). Patterns of decision making in multihospital systems. Journal of Health and Social Behavior, 27(1), 14-27.

Alexander, J., Lewis, B., \& Morrisey, M. (1985). Acquisition strategies of multihospital systems. Health Affairs, 4(3), 49-66.

Alexander, J., \& Morrisey, M. (1988). Hospital selection into multihospital systems: The effects of market, management and mission. Medical Care, 26(2), 159-176.

Alexander, J., \& Morrisey, M. (1989). A resource dependence model of hospital contract management. Health Services Research, 24(2), 259-289.

Allison, P.D. (1985). Event history analysis. Beverly Hills, CA: Sage Publications, Inc.

Belsley, D.A., Kuh, E., \& Welsch, R.E. (1980). Regression diagnostics. New York, NY: John Wiley.

Berry, D.E., Tucker T., \& Seavey, J. (1987). Efficacy of system management of ownership as options for distressed small rural hospitals. The Journal of Rural Health, 3(2), 61-75.
Cameron, K.S., Kim, M.U., \& Whetten, D.A. (1987a). Organizational effects of decline and turbulence. Administrative Science Quarterly, 32, 222-240.

Cameron, K.S., Whetten, D.A., \& Kim, M.U. (1987b), Organizational dysfunction of decline. Academy of Management Journal, 30(1), 126-138.

Cannedy, L.L., Pointer, D., \& Ruchlin, H.S. (1973). Viability and hospital failure: Methodological considerations and empirical evidence. Health Services Research, 8(1), 27-36.

Cox, D.R. (1972). Regression models and life tables. Journal of the Royal Statistical Society, 34, 187-220.

Erman, D.A. (1990). Rural health care: The future of the hospital. Medical Care Review, 47(1), 33-73.

Erman, D.A., \& Gabel, J. (1984). Multihospital systems: Issues and empirical findings. Health Affairs, 3(1), 50-64.

Hambrick, D., \& D'Aveni, R. (1988). Large corporate failures as downward spirals. Administrative Science Quarterly, 33, 1-23.

Hart, L.G., Amundson, B.A., \& Rosenblatt, R.A. (1990). Is there a role for the small rural hospital? The Journal of Rural Health, 6(2), 101-118.

Institute of Medicine. (1986). For-profit enterprise in health care. Washington, DC: National Academy Press.

Kennedy, L., \& Dumas, M.B. (1983). Hospital closures and survivals: An analysis of operating characteristics and regulatory mechanisms in three states. Health Services Research, 18(4), 489-512.

Longo, D.R., \& Chase, G.A. (1984). Structural determinants of hospital closure. Medical Care, 22(5), 388-402.

Mayer, J.D., Kohlenberg E.R., Sieferman G.E., \& Rosenblatt R.A. (1987). Patterns of rural hospital closure in the United States. Social Science in Medicine, 24(4), 327-334.

Mick, S.S., \& Morlock, L.L. (1990). America's rural hospitals: A selective review of 1980s research. The Journal of Rural Health, 6(4), 437-466.

Morrisey, M., \& Alexander, J. (1987). Hospital acquisition or contract management: A theory of strategic choice. Health Care Management Review, 12(4), 21-30.

Moscovice, I.S. (1989). Rural hospitals: A literature synthesis and health services research agenda. Health Services Research, 23(6), 891-930.

Mullner, R.M., \& McNeil, D. (1986). Rural and urban hospital closures: A comparison. Health Affairs, 5 (3), 131-141.

Mullner, R.M., Rydman, R.J., Whiteis, D.G., \& Rich, R.F. (1989). Rural community hospitals and factors correlated with their risk of closing. Public Health Reports, 104(4), 315-325.

Mullner, R.M., \& Whiteis, D.G. (1988). Rural community hospital closure and health policy. Health Policy, 10, 123-135.

Rose, M.G. (1983). Can hospital relocations and closures be stopped through the legal system. Health Services Research, 18(4), 551-574.

Shortell, S.M. (1988). The evolution of hospital systems: Unfulfilled promises and self-fulfilling prophesies. Medical Care Review, $45,177-214$.

Smith, H.L., \& Piland, N.F. (1990). Strategic adaptations to PPS by rural hospitals: Implications for theory and research. The Journal of Rural Health, 6(2), 140-160.

U.S. General Accounting Office. (1990). Rural hospitals: Factors that affect risk of closure (GAO Publication No. GAO/HRD-90-67). Washington, DC: Author.

Whetten, D.A. (1987). Organizational growth and decline processes. Annual Review of Sociology, 13, 335-358.

Zuckerman, H.S. (1979). Multi-institutional systems: Promise and performance. Inquiry, 16, 291-314. 